\title{
Fluvoxamine, melatonin and COVID-19
}

\author{
George M. Anderson ${ }^{1}$ (1)
}

Received: 19 November 2020 / Accepted: 14 December 2020 / Published online: 4 January 2021

(C) The Author(s), under exclusive licence to Springer-Verlag GmbH, DE part of Springer Nature 2021

The recent report of Lenze and colleagues (Lenze et al. 2020) indicates that the selective serotonin reuptake inhibitor (SSRI) fluvoxamine might reduce the rate of clinical deterioration in outpatients with symptomatic COVID-19. Though limited by small sample sizes (n's of 72 and 80) and brief duration, largescale follow-up studies appear definitely warranted.

The authors' stated rationale for testing fluvoxamine is its agonistic effects at the sigma-1 receptor (S1R), as stimulation of the S1R receptor is reported to reduce damaging effects of the inflammatory response. We would like to point out that fluvoxamine might also exert beneficial effects in COVID patients through its well-characterized ability to substantially increase ( 2-3-fold) nighttime plasma levels of melatonin. This increase appears to result from fluvoxamine's inhibition of the melatonin-metabolizing liver enzymes CYP1A2 and CYP2C19 (von Bahr et al. 2000).

The potential utility of melatonin in treating COVID patients has not gone unnoticed, with a November 16, 2020, PubMed search combining melatonin and COVID producing 54 citations. As discussed in a recent review (Cardinali et al. 2020), melatonin might counteract the consequences of COVID-19 via salutary effects on the sleep/wake cycle and more generally on chronobiology, as well as through its antioxidant and anti-inflammatory effects. All of these effects could be especially important in the elderly given their compromised immune response, their reduced production of melatonin, and their typically suboptimal circadian rhythmicity.

Follow-up studies of COVID-19 patients might well benefit from a consideration of the role of melatonin in the response to fluvoxamine. This could include the measurement of plasma or urinary melatonin (or both) before and during drug administration. The closely related matters of chronobiology and circadian rhythmicity could be examined or perhaps controlled by attention to sleep hygiene and lighting conditions (Kamdar et al. 2017). Finally, it is possible that the coadministration of fluvoxamine and timed melatonin might be especially beneficial.

\section{References}

Cardinali DP, Brown GM, Reiter RJ, Pandi-Perumal SR (2020) Elderly as a high-risk group during COVID-19 pandemic: effect of circadian misalignment, sleep dysregulation and melatonin administration. Sleep Vigil 26:1-7. https://doi.org/10.1007/s41782-020-00111-7

Kamdar BB, Martin JL, Needham DM (2017) Noise and light pollution in the hospital: a call for action. J Hosp Med 12(10):861-862

Lenze EJ, Mattar C, Zorumski CF, Stevens A, Schweiger J, Nicol GE, Miller JP, Yang L, Yingling M, Avidan MS, Reiersen AM (2020) Fluvoxamine vs placebo and clinical deterioration in outpatients with symptomatic COVID-19: a randomized clinical trial. JAMA. 324:2292-2300. https://doi.org/10.1001/jama.2020.22760

von Bahr C, Ursing C, Yasui N, Tybring G, Bertilsson L, Röjdmark S (2000) Fluvoxamine but not citalopram increases serum melatonin in healthy subjects- an indication that cytochrome P450 CYP1A2 and CYP2C19 hydroxylate melatonin. Eur J Clin Pharmacol 56(2): $123-127$

Publisher's note Springer Nature remains neutral with regard to jurisdictional claims in published maps and institutional affiliations.
George M. Anderson

george.anderson@yale.edu

1 Child Study Center and the Department of Laboratory Medicine, Yale University School of Medicine, 230 S. Frontage Rd., New Haven, CT 06525, USA 